\title{
World view theory and the conceptualisation of space in mathematics education
}

(an abridged version of this paper was presented at the SAARMSTE Conference, Cape Town in January 2004)

\author{
Marc Schäfer \\ Rhodes University \\ email: M.Schafer@ru.ac.za
}

\section{Introduction}

The cornerstone of current education trends that recognise prior knowledge as fundamental to the learning process, is the notion that beliefs and experiences that learners bring to the classroom influence their learning experiences in the classroom (Cobern, Gibson and Underwood, 1999). World view research in science education has proved an important tool in unravelling learners' beliefs and perceptions in an attempt to better understand what experiences they bring to a classroom situation. Cobern (1991, 1993, 1994, 1996, 1997) has successfully spearheaded much of the world view research in that field, with particular emphasis on learners' perceptions and understanding of nature. Very little, if any, world view research has been conducted in a mathematics education context. This paper reports on a $\mathrm{PhD}$ study that specifically employed a world view research strategy in exploring Grade 11 learners' perceptions of space in an attempt to shed light on their broader spatial conceptualisation. Before describing the methodological model which framed the world view research of the study, this paper will briefly discuss the three fundamental theoretical concepts that underpinned this research: spatial conceptualisation, space, and world view. Traditionally, comment on and analysis of learners' spatial conceptualization was framed around performance in pen-and-paper tests. It is, however, the assertion of this research that performance in pen-and-paper tests provides only part of a more comprehensive picture. Spatial conceptualisation is seen as a complex and rich blend of spatial performance 'measured' in pen-andpaper tests, and a personal world view of space.

\section{The theoretical framework}

\section{Spatial conceptualization}

It is a common perception that spatial understanding is fundamental to the understanding and "appreciation of our inherently geometric world" (NCTM, 1989) in general, and to mathematical cognition in particular. Battista et al. (1982) recognised this by suggesting that spatial thinking is an important aspect of mathematical performance. Much research has focused on the relationship between spatial understanding and mathematics achievement (Bishop, 1980). Educators and policymakers the world over have intuitively recognised the role of spatial thinking and most mathematics curricula incorporate aspects of developing spatial thinking, usually in the form of formal geometry.

There is, however, little consensus on the concept of space, even while most western mathematics curricula are firmly rooted in a Euclidean paradigm which sees space as a measurable and rational system. Euclidean space is seen as ordered, where shapes are measurable and positioned in a definite manner (Euclid, 1956). There is a sense of geometry - "the branch of Mathematics concerned with the properties and relations of points, lines, surfaces and solids; the relative arrangement of objects or parts" (Concise Oxford Dictionary, 1995). Newtonian space is consistent with Euclidean space in terms of its sense of order and tangibility. It affirms the "reality of space" (Gardner, 1999) and maintains that space exists independently of the subject's awareness. Kantian space, on the other hand, suggests that "space (and time) are not features of absolute reality but only forms of sensibility, elements of our subjective cognitive constitution, and that everything that has spatial properties - all the objects of our experience - are mere appearances as opposed to things in themselves” (Gardner, 1999). 


\section{Marc Schäfer}

This implies that space should not be conceptualised in terms of objective features only. In Kant's concept of space, the space is independent of its content. This means that our subjective understandings and experiences form an integral part of our overall perception of space. Kant suggests that the order we find in nature is the order that exists in our minds, an order which is embedded in or reflects our own structure of mind (Stumpf, 1994; Want and Klimowski, 1996).

There is a tendency in current thinking to embrace a broader view of geometry. The post-1994 curriculum for Mathematics in South Africa, for example, sees space and shape within a context of social experiences. One of the specific outcomes of the mathematics curriculum suggests that learners need to be able to "describe and represent experiences with shape, space, time and motion, using all available senses” (South Africa, 1997). This apparent shift is consistent with a global epistemological paradigm move towards recognising that cognition is an active and complex process of social interaction.

There has been a plethora of research literature on spatial conceptualization and its importance in the cognitive development of spatial capacity. Much of the literature, however, is in agreement that there is little consensus in the terminology and definitions used. There also appears to be little consensus in the theoretical frameworks underpinning spatial development. Nothing much has changed since Battista's et al. (1982:332) comment that "the role that spatial thinking plays in mathematical performance has not been adequately described", or Bishop's (1980) lament that there exist inconsistencies in terminology and methodology of research in the general discourse of spatial ability.

For the sake of ensuring clarity and seeking consistency in the use of terminology from the literature (Bishop, 1980), this research project was shaped around the following fundamental concepts of spatial conceptualisation:

Spatial capacity: the all-encompassing concept which embraces spatial visualisation, orientation, perception and ability. In this research spatial capacity refers in particular to that aspect of spatial conceptualisation which is measurable in a pen-andpaper and/or hands-on activity test.

Spatial visualisation: the ability to manipulate mentally, rotate, twist, or invert a pictorially or physically presented stimulus object. The underlying ability in spatial visualisation appears to be connected to movement, transformation and manipulation. It is dynamic and involves motion.

Spatial orientation: the ability to recognise the identity of an object when it is seen from different angles. It is the ability to make sense of spatial orientations of an object relative to different positions of itself or of other objects.

Spatial conceptualisation: the fundamental concept that ultimately incorporates spatial capacity and perceptions of space.

\section{World view}

As Funk (2001) suggests, the meaning of the term world view seems self-evident. The German translation Weltanschauung implies a perception of the world, "a conception of the world" or a "particular philosophy of life" (Concise Oxford Dictionary, 1995). The 19th century German philosopher Wilhelm Dilthey was especially interested in world views. "He was fascinated by the familiar, yet vexing, fact that world views vary so widely and conflict so sharply even when they are based on the reasoned arguments of philosophers" (Rickman, 1979:47). According to Dilthey (Rickman, 1976:141) "the formation of world views is determined by the will to stabilize the conception of the world, the evaluation of life and the guidance of the will". World views are dynamic and develop under varied conditions. Dilthey (Rickman, 1976:139) asserts that:

...climate, race and nationality, determined by history, and the development of states, the temporal delimitation into epochs and ages in which nations cooperate, combine to produce the special conditions which influence the rise of differences in world views.

Dilthey's views need to be seen in context with his own epistemological assumptions. He assumes that "we know the world through our feelings and strivings as well as through our sense impressions and thinking” (Dilthey, cited in Rickman, 1976:15). The epistemological underpinning of this study has elements of Dilthey's assumption and is rooted in the idea that an individual's cognition is a complex process which is informed by world views and presuppositions.

Funk (2001) makes an interesting observation with which I strongly identify. He suggests that an individual's world view may not always be explicit. Few people take time to thoroughly think out, much less articulate, their world view. When exploring 
and discussing their world views the participants of this research project intimated that they had never really thought and talked about their presuppositions and conceptions of the world around them.

Holmes' work on Dilthey, as cited in Cobern (1991), suggests that our world view, or Weltanschauung, initially rests on a more fundamental implicit world picture, or Weltbild, which develops in the context of the world in which we live, or Lebensbild. This concept of world view has influenced current world view theorists and has occupied an important place in anthropology, but according to Kearney (1984) no comprehensive model had been formulated prior to his logicostructural model which will be discussed later. He refers to world view as a "culturally organised macrothought: those dynamically interrelated basic cognitive assumptions of a people that determine much of their behaviour and decision making" (Kearney, 1984:1). Cobern (1991:19), a scienceeducation researcher who has embraced the notion of world-view theory in science-education research, takes Kearney's definition a step further and asserts that "a world view inclines one to a particular way of thinking”. In Cobern's work (1991), which rests heavily on Kearney's (1984) theoretical framework, world-view research focuses on students' presupposition about their world, that is, their epistemological macrostructures. One of the central themes of this research is Cobern's (1991:20) observation that "knowing more about students' world views should help researchers come to a better understanding of conceptual change by providing a more complete understanding of conceptual structure. It should enable educators to better understand students' attitudes and achievement in general”.

Kearney's (1984:2) unique theoretical worldview framework is based on the assumption that a world view is a "dynamic, more or less internally consistent system which demonstrates logical and structural regularities". He suggests that the structural composition of a world view consists of seven universals, or cognitive categories (Cobern, 1991): Self, The Other (Non-Self), Relationship, Classification, Causality, Space and Time. Kearney refers to his model as logico-structural integration (Kearney, 1984) because he asserts that the worldview categories are filled with "logically consistent presuppositions about reality” (Cobern, 1991:39).

As Slay (2000) notes in reviewing these universals, they can serve as an effective framework for analysis of a world view. Although there is a recognition that the universals above need to be seen holistically, my research specifically focused on the category space and, in conjunction with exploring issues of spatial capacity, investigated presuppositions about space held by 32 Grade 11 students. It is my assertion that spatial conceptualisation is a complex blend of spatial capacity and world view of space. As it is beyond the scope of this paper to consider all of Kearney's universals, I will dwell only on the space universal. For details regarding the other six universals refer to Cobern (1991), Slay (2000) and Schäfer (2003).

\section{World view in the context of this research}

The key theoretical issues that are particularly relevant to this study and specifically frame this research in order to achieve part of the objectives are:

- the systematic application of the logicostructural model as proposed by Kearney (1984) to explore world views of space;

- the creation and exploration of world-view profiles to illustrate students' presupposition about space.

\section{Space}

Space means many things to many people and is key to this study. In Kearney's (1984) logico-structural model, space is the seventh universal, although he links this very closely to time. He theorises that as things are located in space, they are also inextricably located in time. For the purpose and scope of this study, however, space and time have been segregated. When looking at the world-view aspect of space, as wide a definition for space as possible is sought. In Kearney's work (1984:92) he observed that space is used to refer "to many different concepts, ranging from an easily measurable geographical space to more metaphorical usages such as psychological, life and mathematical space”. In his anthropological dealing with world-view aspects of space, Kearney (1984) was mainly concerned with the relationship between the environmental space of a people and their images of it. In my attempt to ground this research in the literature, my readings led me along a fascinating path of interesting interpretations of space. This journey facilitated transient visits to Gestalt psychology, ancient Greek philosophy, mathematics and modern western philosophy. As it is beyond the scope of this short paper to refer to these visits in detail, I provide only a very short and superficial overview. For further details, refer to Schäfer (2003). 


\section{Marc Schäfer}

Absolute and relative space: Among theorists in Gestalt psychology, Koffka (1935) distinguished between geographical environment (absolute space) and the behavioural environment (relative space). He held that the geographical environment is 'stimulus providing' and that the behavioural environment depends upon the geographical environment and the organism itself.

Mathematical space, physical space and psychological space: Downs and Stea (1973) cite Lewin (another Gestalt psychologist), who stressed the relationship of and distinctions among mathematical space, physical space and psychological life space. These concepts of space resemble those of Koffka, who collapsed mathematical and physical space into absolute space and referred to Lewin's psychological space as relative space. In Greek philosophy Plato and Aristotle explored the notion of space in terms of its physical characteristics and boundaries. Plato viewed space as a receptacle or vessel for objects (Caygill, 1995), whereas Aristotle suggested that space is "the boundary of the containing body at which it is in contact with the contained" (Aristotle cited in McKeon, 1941:31). One of the most influential geometers who speculated with mathematical space, Euclid, acquired his early education in Plato's Academy (Hollingdale, 1994) and was taught by geometers from that school of thought (Euclid, 1956). In his work, The Elements, regarded as one of the most influential texts of mathematics (Hollingdale, 1994), Euclid employed a precise, innovative, rigorous and logical methodology (using assumptions, postulates and theorems) to describe and prove geometrical concepts (Mlodinow, 2001), which at the time informed the frames of reference for spatial understanding.

Descartes, in his quest to describe the universe in terms of definable co-ordinates or positions, leaned towards the Platonic position, with the identification of space with "extension in length, breadth, and depth" (Descartes cited in Caygill, 1995:368). Building on the work of Galileo, Descartes was one of the first advocates of geometrical physics. Sorrell (1987) suggests that Descartes' physics was constructed out of mathematical facts about material things, from facts about size, shape, composition and speed. Descartes claimed that "he was in the habit of turning all problems into geometry" (Davis and Hersch, 1986). Descartes asserted that mathematics (geometry in particular), which was based on direct observation, is fundamental to understanding the universe. The result of this reductionist approach was a very heavily structured and grid-like outlook on space. Indeed Descartes is credited as the founder of the Cartesian plane, the foundation for coordinate geometry, a system which facilitates the solving of algebraic problems through applying geometric principles. In his book La Geometrie he suggests that "any problem in geometry can easily be reduced to such terms that a knowledge of the lengths of certain straight lines is sufficient for its construction" (Descartes, 1925:2)

Newton distinguished between absolute space and relative space. In his view, absolute space is "without relation to anything external, remains always similar and immovable" (Newton cited in Caygill, 1995:368) - it is the space of God. Relative space, on the other hand, "is some movable dimension or measure of absolute spaces; which our senses determine by its position to bodies; and which is commonly taken for immovable space" (Newton cited in Caygill (1995:368). According to Gardner (1999), Newton's view is of space as an absolutely real, self-subsistent 'container' which would exist even if no physical objects were contained within it.

Leibniz refutes both Descartes' and Newton's views that space is in some sense substantial. He argues that space is relative (Caygill, 1995). Leibniz suggests that the universe is made up of monads, which have no shape or size. A monad is a point, not a mathematical or a physical point but a metaphysically existent point. Whereas Descartes is arguing for a rational and material space, Leibniz clearly proposes a space consisting of non-corporeal forms. Leibniz, however, says that there must be some relation between all the monads which make up the universe, some explanation for their orderly actions which Leibniz refers to as pre-established harmony (Stumpf, 1994). Leibnizian view is of space as a logical construction out of relations between objects (Gardner, 1999).

It can be conceived that in Newton's absolutist model of space, "the universe could shift its position in space and could have been created at a different time from that at which it actually came into existence” (Gardner, 1999:71). Leibniz's relational view of space, however, "grants the plain possibility of empty space and empty time”.

Locke avoids the material/non-material debate by arguing that space is a simple concept based entirely on our senses of sight and touch. Space therefore is "a simple idea which is modified into measures of distance and into figures" (Caygill, 1995:368).

Kant's view on space changed and evolved over time. He initially identified with the Leibnizian definition of space as "the objective relation of 
substances” (Caygill, 1995:369). With the emergence of a revised definition of metaphysics, which was no longer equated with the science of substantial forces but was identified as the science of the limits of human cognition, Kant turned to a more subjective understanding of space. He asserted that space is an intuition (Gardner, 1999). More specifically, Kant speaks of space as a priori intuition which means that it is not derived from experience. This is to say that a perception of space is pure and cannot be derived from either sensibility or understanding. "Space cannot be derived from outer experience” (Caygill, 1995:372).

Personal space: Personal space refers to "an area with invisible boundaries surrounding a person's body into which intruders may not come” (Sommer, 1969:26). It is not spherical in shape, according to Sommer (1969), as some people are able to tolerate closer presence of strangers at their sides than directly in front. Further, the extent of this space changes from individual to individual as some people like to be close enough for warmth and comradeship whereas others like to be far enough to avoid space invasion. The invasion of personal space is an intrusion into a person's self-boundaries. These may be physical or they may be psychological. I may be made uncomfortable by an individual's physical closeness; or I may feel uneasy at an individual's intrusion into my relationship space with another person. When exploring issues of space with my sample the notion of personal space surfaced on numerous occasions.

Space in the context of this research: One of the central aims of this research was to construct individual world-view profiles of space of the participating pupils. As I sought as wide a perception of space as possible I consciously tried not to let the above definitions and understandings dictate my interview approach. I therefore steered clear of providing a single dogmatic definition of space. As it happened, it was fascinating to experience how many of the above ideas emerged throughout the conversations. Many of the subjects took a Platonic stance and saw space as something empty into which objects could be placed. Others identified with the personal dimension of space and articulated how they treasured their own space bubble. Others again adopted a more Kantian perspective and equated space with their feelings as something that feels good and beautiful. Many saw space merely in its physical and planetary (cosmic) form while others took the Newtonian and Cartesian stance and saw space as an ordered, absolute and definable system. The different ideas and positions on space were not mutually exclusive - there was a lot of overlap and diffusion of different ideas.

\section{An interpretive methodology}

The fundamental research question that this research aimed to answer was whether an understanding of a world-view-theory approach contributed towards the exploration of an individual's spatial conceptualisation.

To answer the question the study pursued and was structured around the following objectives:

1. to explore spatial capacity (spatial visualization and orientation skills) using both pen-and-paper test items and hands-on activities;

2. to explore spatial conceptualization by engaging in world-view profiles of space using a logicostructural approach;

3. to investigate consistencies and relationships between spatial capacity, world views and aspects of mathematics performance of Grade 11 learners; and

4. to show that spatial conceptualisation is a rich and complex blend of spatial capacity and world view.

This paper only reports on the issue of worldview profiles.

The study was grounded in an interpretivistnaturalistic paradigm as it was concerned with the individual and was aimed at understanding the subjective world of the individual (Schwandt, 1994; Lincoln and Guba, 1985; Denzin and Lincoln, 1994; Cohen and Manion, 1994; Cohen, Manion and Morisson, 2000), and made use of multiple sources and types of data (Le Compte, Millroy and Preissle, 1993) to ensure credibility (Lincoln and Guba, 1985). This research comprised a multi-sited case study (Stake, 2000) involving a group of 32 Grade 11 learners from five different secondary schools in the Eastern Cape, a province of South Africa, from a diverse range of cultural and socio-economic backgrounds. Several techniques for data collection were employed. They included the use of questionnaires, administering a pen-and-paper and a hands-on activity test, and engaging in conversations.

The interview was used in this research as the dominant technique to tease out the participants' own view of space. As I felt that the concept of space could be very abstract, complex and possibly inaccessible for many of them and consequently a very difficult topic for conversation, I modelled my 


\section{Marc Schäfer}

strategy on Cobern's (1993) and Slay's (2000) world-view research in which they made use of a framework of themes around which conversations and interviews could be structured. I was reluctant to over-structure my interviews and so stifle spontaneous conversation and insight. Nevertheless, I thought that some enabling framework which remained consistent for all the 32 interviews would facilitate the eventual analysis more effectively than having to analyse 32 totally open-ended conversations. In retrospect this proved to be an important aspect of the methodological design, serving as a frame of reference for analysing the conversations and building meaningful concept maps. Throughout the interviews and conversations I consciously encouraged the participants to talk as freely and generally as they could. I avoided coercing them into a discursive domain that could be described specifically as "scientific" or "mathematical."

The framework originally devised by Cobern (1993:935) relied on a set of "bipolar descriptive codes". These bipolar codes (also sometimes called vector pairs), representing the opposing ends of a continuum, were used to explore students' conceptualisation of and beliefs about nature. The set of bipolar codes, also referred to as vector pairs, that Cobern used were: naturalism and religion, chaos and order, mystery and knowledge, function and purpose, mundane and special, and science and no science.

In addition to a few extra vector pairs, I made use of Cobern's (1993) model above (see Table 1), and for each of the pairs I devised some guiding questions that would frame the structure of the interviews.

\begin{tabular}{|rl|}
\hline Naturalism & - Religion \\
Chaos & - Order \\
Mystery & - Knowledge \\
Function & - Purpose \\
Mundane & - Special \\
Mathematical & - Non-mathematical \\
(Cartesian & - non-cartesian) \\
Finite & - Infinite \\
Tangible & - Non-tangible \\
Internal & - External \\
\hline
\end{tabular}

Table 1: Framework for interviewing using bipolar codes.

Citing Jones, Cobern (1993:939) suggests that "bipolar coding involves selecting two related codes that together distinguish a range of beliefs with respect to one presupposition". For example, as described below, people could for example believe space to be orderly, chaotic, or something in between the two extremes. The nine descriptive pairs of bipolar codes as used in this study, are discussed below.

\section{Naturalism and religion}

Naturalism, as used in this study, refers to the belief that "material or physical causation provides the basis" (Cobern, 1993:939) for understanding space. It fundamentally rules out theistic involvement in space. Religion, however, is the opposite - it asserts the involvement of the supernatural in space.

\section{Chaos and order}

Chaos implies that space is changeable, random and unpredictable, whereas order implies the opposite space is predictable, based on rules and principles.

\section{Mystery and knowledge}

This vector pair describes "the extent to which one believes [space] to be fathomable" (Cobern, 1993:942). Those who find space mysterious are clearly more impressed with what is not known than what is, whereas those who find space knowable have significant material understanding of space or events in space (Cobern, 1993).

\section{Function and purpose}

A function explanation of space refers to a "teleonmic or a structure/function explanation of space" whereas purpose explanations refer to "transcendent purpose or cosmic teleology" (Cobern, 1993:944).

\section{Mundane and special}

This vector pair seeks to deconstruct whether space is perceived as something "beyond the ordinary" (Cobern 1993:946) or something mundane and prosaic.

\section{Mathematical and non-mathematical}

As this study is situated in a mathematical context there was an interest in the extent to which mathematics informed a participant's view of space.

\section{Finite and infinite}

This vector pair seeks to describe the extent to which participants view space as an infinite concept (infinitely large or infinitely small) or whether they see space in terms of defined parameters.

\section{Tangible and non-tangible}

A 'tangible' explanation of space is one where space is perceived as something that one can touch and 
see, whereas a 'non-tangible' perception of space is characterised by mystery and abstractions.

\section{Internal and external}

This vector pair seeks to explore the extent to which space is perceived as a phenomenon "out there" or something which is internalised and part of the self. they were finalised and analysed. The bi-polar codes assisted in clustering themes. The concept maps were effective and useful in establishing meaningful overviews of the individual world views of the participants. They gave an interesting glimpse into the participants' perception of space and illustrated the richness and complexities of their

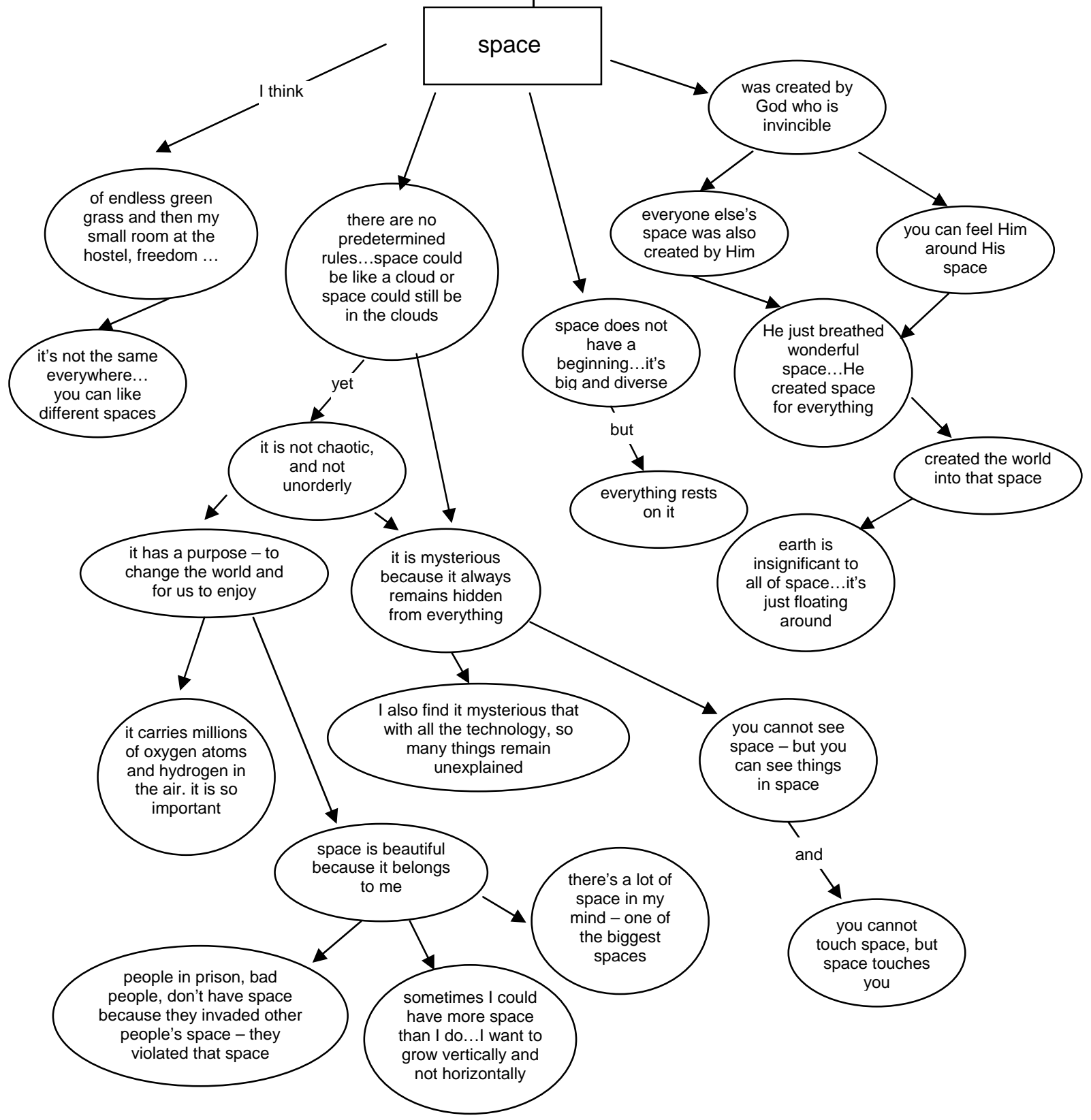

Figure 1: A concept map of the conversation of one participant

The interview transcripts then formed the basis for the construction of world-view profiles in the form of concept maps. Figure 1 provides an example of one participant's concept map. The transcripts and concept maps were reviewed and edited by the participants (member-checked) before perceptions. The world-view profiles provided fascinating insight into what the participants thought of space. As, however, the study aimed to provide as comprehensive a picture as possible of the sample's conceptualisation of space, I considered it necessary to also establish some sense of how the participants thought of space. I therefore 


\section{Marc Schäfer}

investigated beyond the content level and explored some of the higher-order thinking processes that the participants were involved in and engaged in a metalevel analysis. The extent to which the participants' perception of space related to their spatial conceptualisation in terms of spatial capacity was, however, nigh impossible to establish. A deeper level of analysis was therefore required. The participants' dialogue therefore evolved into a vehicle through which a meta-analysis of higherorder thinking was conducted. The world-view profiles of space thus emerged as important tools for exploring meta-level thinking.

\section{A process of meta-analysis}

Through the engagement of a consensual validation team consisting of three expert researchers and I, a methodological model was developed which facilitated a process of meta-analysis. The concept of validation was grounded in the notion that "validation is not just seen as part of a final product control process or verification, but rather a continuous process of credibility, growth and understanding” (Schäfer, 1999). Through a process of discussion and seeking consensus amongst the team, five meta-themes (criteria) that characterised the participants' thinking skills in this study were identified. They were:

- $\quad$ the capacity to abstract (abstraction);

- the capacity of insight (insightful);

- the capacity to deal with complex concepts and issues (complexity);

- the capacity to critically engage (critical);

- the capacity to be imaginative (imagination).

For detailed definitions and explications of the above criteria refer to Schäfer (2003).

It was felt inappropriate to attach a quantity for each participant's "performance" in terms of the criteria. Instead, each participant was positioned on a continuum in each of the meta-criteria. Thus the notion of a "meta-profile" developed (Schäfer, 2003). The idea of a "meta-star" developed whereby each arm of the star represented each participant's emphasis on the five meta-criteria. For example, a longer "abstraction" arm than "critical" arm would suggest a better capacity to abstract than to critically engage. Figure 2 shows an example of one of the participants' meta-stars.

The respective lengths of the arms of each metastar were arrived at through consensus amongst the members of the validation team. This process involved numerous rounds of analyses and discussion.

The collection of meta-stars then formed the basis for a meta-narrative which complemented and supplemented the content-narrative based on the various world-view profiles. The meta-stars could also be grouped into numerous clusters such as schools and gender for interesting comparisons and insight. It needs to be emphasised that the metastars describe individual meta-profiles relative to the themes and criteria of this study.

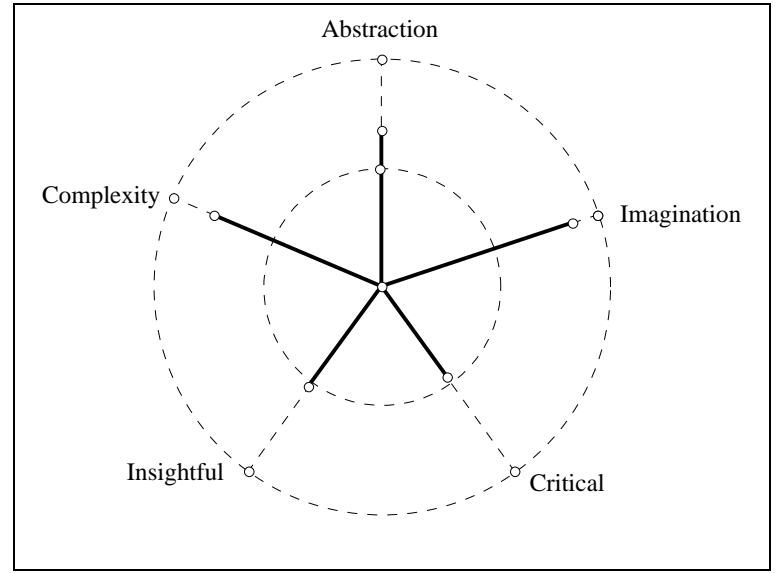

Figure 2: The meta-star of one of the participants

\section{Conclusion}

The general world view of space of the sample was characterised by rich, complex and multifaceted ideas. Space was seen as:

- having a strong religious element;

- relatively orderly, peaceful and underpinned by design;

- somewhat obscure and mysterious;

- special and beautiful;

- something which has direction;

- making us insignificant and small;

- having no beginning and no end;

- something which we cannot touch, yet feel;

- something that is visible in the sense that we can see that there is nothing there.

The overall perception of space of the sample leant towards a Newtonian division of absolute and relative space. In terms of magnitude it regarded space as infinite thereby refuting the Platonic position which asserts that space has length, depth and breadth. In terms of the Cartesian reductionist and grid-like outlook on space, this sample preferred to view space as mysterious, infinite and somewhat 
obscure. It often referred to space in Kantian terms and related to space in terms of subjective feelings.

On a meta-level it was found that generally the sample engaged at a relatively low level of critical engagement. Interestingly, the girls were rated at a higher level than their male counterparts for their capacity to abstract and be complex, whereas the males rated higher for their capacity to show insight, be imaginative and be critical.

Kearney's (1984) logico-structuralist model is not without its problems. Although the framework of bipolar codes was meant to enable the establishment of world-view profiles, it can be argued that the framework was too rigid, prescriptive and linear in its approach and did not allow for deviation and flexibility. It can also be argued that the bipolar codes in themselves were too limiting and restrictive. For example, in the first bipolar code, the assumption was made that the antithesis of naturalism is religion. Although the notion of a bipolar continuum provided for compromise and a softening of mutual exclusivity, it did not challenge the fundamental assumption of bipolarity. The same can be said for the other codes. By the same token it can be reasoned that the strength of the logico-structuralist approach lies in its structure and rigour. World view is a complex concept to describe and explore, and Kearney's model provided a workable framework and point of reference for researching world views.

In terms of a more global and comprehensive world view, it could be argued that this study focused too narrowly on the space universal at the expense of the other six universals. This study was particularly concerned with the presuppositions of space in conjunction with spatial capacity, and hence focused only on the space universal. It is thus acknowledged that the world-view claims made in this study pertain only to the understanding of space and consequently reflects only a small aspect of a more global world view.

The relevance of this study to mathematics education needs to be seen in the context of recognising prior knowledge, beliefs, presuppositions and experiences. The notion of a world view is fundamental to the unravelling of prior beliefs and it is hoped that the qualitative methodological model described in this paper will contribute to further world view studies.

\section{References}

BATTISTA, M.T., TALSMA, G. AND WHEATLEY, G.H., 1982, “The importance of spatial visualization and cognitive development for geometry learning in pre-service elementary teachers" in Journal for Research in Mathematics Education, 13(5), pp. 332 - 340

BISHOP, A.J., 1980, "Spatial abilities and mathematics education: A review" in Educational Studies in Mathematics, 11, pp. 257 $-269$

CAYGILL, H., 1995, A Kant dictionary, Oxford: Blackwell

COBERN, W.W., 1991, World view theory and science education research. NARST

Monograph No.3, Manhattan, Kansas: National Association for Research in Science Teaching

COBERN, W.W., 1993, “College students' conceptualisation of nature: An interpretive world view analysis" in Journal of Research in Science Teaching, 30(8), pp. 935 - 951

COBERN, W.W., 1994, "Word view, culture, and science education" in Science Education International, 5(4), pp. 5 - 8

COBERN, W.W., 1996, "World view theory and conceptual change in science education" in Science Education, 80(5), pp. 579 - 610

COBERN, W.W., 1997, "Distinguishing sciencerelated variations in the causal universal of college students' world views", Electronic Journal of Science Education, 1(3) http://unr.rdu/homepage/jcannon/ejsecobern.html/

COBERN, W.W., GIBSON, A.T. AND UNDERWOOD, S.A., 1999, "Conceptualisation of Nature: An interpretive study of 16 ninth graders' everyday thinking” in Journal of Research in Science Teaching, 36(5), pp. 541 564

COHEN, L. AND MANION, L., 1994, Research methods in education ( $4^{\text {th }}$ ed.), London: Routledge

COHEN, L., MANION, L. AND MORRISON, K., 2000, Research methods in education ( $5^{\text {th }}$ ed.), London: Routledge.

CONCISE OXFORD DICTIONARY, $9^{\text {th }}$ ed., 1995, Oxford: Clarendon Press

DAVIS, P.J. AND HERSCH, R., 1986, Descartes' dream, London: Penguin Books

DESCARTES, R., 1925, The geometry, New York: Dover Publications

DENZIN, N.K. AND LINCOLN, Y.S., 1994, "Entering the field of qualitative research" in Denzin, N.K. and Lincoln, Y.S. (Eds.), Handbook of qualitative research $\left(2^{\text {nd }}\right.$ ed.), pp. 1 - 17, London: SAGE Publications

DOWNS, R.M. AND STEA, D., 1973, "Introduction" in Downs, R.M., and Stea, D. (Eds.), Image and environment, pp.1 - 7, London: Edward Arnold 


\section{Marc Schäfer}

EUCLID, 1956, The thirteen books of the elements: Volume I, New York: Dover Publications.

FUNK, K., 2001, What is a worldview?, at http://engr.oregonstate.edu/ funkk/Personal/worl dview.html

GARDNER, S., 1999, Kant and the critique of pure reason, London: Routledge.

HOLLINGDALE, S., 1994, Makers of mathematics, London: Penguin Books

KEARNEY, M., 1984, World view, California: Chandler \& Sharp Publishers

KOFFKA, K., 1935, Principles of gestalt psychology, New York: Harcourt-Brace

LE COMPTE, M.D., MILLROY, W.L. AND PREISSLE, J., 1992, The handbook of qualitative research in education, London: Academic Press

LINCOLN, Y.S. AND GUBA, E.G., 1985, Naturalistic inquiry, London: SAGE

MCKEON, R., 1941, The basic works of Aristotle, New York: Random House

MLODINOW, L., 2001, Euclid's window: The story of geometry from parallel lines to hyperspace, London: Allen Lane, the Penguin Press

NCTM, 1989, Curriculum and evaluation standards for school mathematics, Reston, Va.: The Council

RICKMAN, H.P., 1979, Wilhelm Dilthey: Pioneer of the human studies, London: Paul Elek

RICKMAN, H.P., 1976, Dilthey: Selected writings, Cambridge: Cambridge University Press

SCHÄFER, M., 1999, Designing and making a difference: An exploration of technology education for rural school teachers,
Unpublished master's thesis, Rhodes University, Grahamstown, South Africa

SCHÄFER, M., 2003, The impact of learners' spatial capacity and world view on their spatial conceptualization: a case study, Unpublished doctoral thesis, Curtin University of Technology, Perth, Australia Also available at http://adt.curtin.edu.au/theses/browse/by_author/ s.html

SCHWANDT, T.A., 1994, "Constructivist, interpretivist approaches to human enquiry" in Denzin, N.K. and Lincoln, Y.S., eds., Handbook of Qualitative Research ( $2^{\text {nd }}$ ed.), $\quad$ pp. 118 137, London: SAGE Publications

SOMMER, R., 1969, Personal space: The behavioural basis of design, Englewood Cliffs, NJ.: Prentice-Hall

SORREL, T., 1987, Descartes: A very short introduction,. Oxford: Oxford University Press

STAKE, R.E., 2000, “Case studies” in Denzin, N.K. and Lincoln, Y.S. (Eds.), Handbook of Qualitative Research (2 ${ }^{\text {nd }}$ ed.), pp. 435 - 454, London: SAGE Publications

SLAY, J., 2000, Culture and conceptualization of nature: An interpretive analysis of Australian and Chinese perspectives, Unpublished doctoral thesis, Curtin University of Technology, Perth, Western Australia

SOUTH AFRICA (REPUBLIC), 1997, Senior Phase (Grades 7 to 9). Policy Document, Pretoria: Government Printer

STUMPF, S.E., 1994, Philosophy: History and problem $\left(5^{\text {th }}\right.$ ed.), New York: McGraw-Hill

WANT, C. AND KLIMOWSKI, A., 1996, Introducing Kant, Cambridge: Icon Books 